\title{
DIREITOS HUMANOS, AÇÃO POLÍTICA E AS SUBJETIVAÇÕES OCEÂNICAS ${ }^{12}$ Edson Teles (Unifesp) ${ }^{3}$ \\ edsonteles@gmail.com
}

Frustrar a catástrofe é realizar uma ação coletiva de liberdade.

Antonio Negri e Félix Guattari (As verdades nômades, p. 8)

Resumo: $\mathrm{O}$ objetivo deste artigo é refletir sobre o modo como as lutas locais e suas movimentações em torno do discurso dos direitos humanos podem ser alçadas à condição de ação política. Trata-se da tentativa de ampliar o conceito de política tendo em vista a potência de transformação contida nos coletivos de subjetividades portadoras de experiências comuns de violência e sofrimento. Fazendo uso do conceito de quilombo, em Beatriz Nascimento, busca-se fundamentar o alargamento da ideia de política a partir de duas configurações: a disputa por territórios e a conectividade entre saberes específicos oriundos das lutas. Para tanto, se fará cotejos do pensamento da autora com a filosofia contemporânea de Michel Foucault, Gilles Deleuze e Félix Guattari. A hipótese é a de que o conceito de ação política demandaria um alargamento em sua formulação de modo a abranger as variadas e singulares formas de resistência cotidianas.

Palavras-chave: conectividade; território; quilombo; corpo; ação política; luta

\footnotetext{
${ }^{1}$ Recebido: 08-01-2018/ Aceito: 25-03-2018/ Publicado online: 07-08-2018.

${ }^{2}$ Este artigo se originou em comunicação no III Encontro Nacional de Filosofia Política Contemporânea, realizado na Universidade Estadual de Londrina (Paraná), entre os dias 23 e 26 de agosto de 2017, momento em que os colegas do Grupo de Trabalho da ANPOF, no mesmo tema do evento, contribuíram com questões fundamentais. Agradeço pelas conversas à turma da disciplina "Ética e Filosofia Política" (Unifesp), do segundo semestre de 2017; a Lea Tosold, por compartilhar impressões sobre Beatriz Nascimento; e, ao parecerista desta Revista. Por fim, agradeço ao auxílio recebido via processo 2015/22723-0, Fundação de Amparo à Pesquisa do Estado de São Paulo (FAPESP).

${ }^{3}$ Edson Teles é Professor de Filosofia Política na Universidade Federal de São Paulo, São Paulo, SP, Brasil.
} 
por direitos.

Nosso propósito é o de refletir sobre a ação política fundamentando-se em seus aspectos conflituosos e de lutas. Não somente um conflito entre beneficiados e excluídos de pactos e contratos sociais que poderiam, finalmente, serem inscritos em direitos. Falamos de lutas de vida e morte, de sangue, violentas, que não se encerram sob o discurso de paz e reconciliação. Sabemos que a tradição da filosofia política, entre autores e teorias modernas e contemporâneas, tende a nos apresentar, por meio, principalmente, dos conceitos de democracia e de estado de direito, a ação política como resultado da representação de um "povo" ou de algum segmento dele. Como se houvesse, fabricado pelos cidadãos, uma estrutura funcionando em prol da estabilidade de relações agonísticas e operando em torno de normalizações e regras. O que se encontra fora deste quadro seriam anomalias sociais que reforçariam ainda mais a demanda pelas máquinas políticas institucionais.

A tradição teórica tem pensado a política - ou ao menos a democrática - como o exercício dos discursos e gestos, quando atos e palavras singulares dos indivíduos ou grupos políticos buscam persuadir maiorias com o fito de transformar o futuro próximo. $\mathrm{O}$ argumento desta tradição pensa "os homens no plural, isto é, os homens na medida em que vivem, se movem e agem neste mundo, [e] só podem experimentar a significação porque podem falar uns com os outros e se fazer entender aos outros e a si mesmos" (ARENDT 2010, p. 5). 
As construções do sujeito cidadão, do partido político, da associação, da nação, da cidadania, dos direitos humanos, juntamente com os valores burgueses, religiosos e morais, por um bom tempo alimentam uma ação política com eficientes subjetivações como a nacionalista, a racista, a fascista, a democrática, o duelo esquerda/direita, a onda autoritária ou os avanços progressistas. Contudo, se há nas experimentações da vida e do social uma linguagem corporal, afetiva, ética e política em constante e plena inovação, há também um discurso e uma ação convencional, pobre e conservadora que visa justamente exercer a função pragmática de controle das novas subjetividades e dos acontecimentos com potencial transformador.

O pensamento político há muito não tem mais como escapar de um grave dilema contemporâneo: como determinada ação de defesa da vida processada fora dos parâmetros do diálogo entre singulares ou do conflito regulado por leis, sem programa político ou organização prévia, insistentemente continua a ser considerada qualquer coisa menos ação política? Não haveria nesta limitação - ou seria bloqueio - do que se concebe como política um controle eficaz diante das várias subjetividades produzidas pela e em favor de profundas transformações econômicas, sociais e culturais? Como conceituar as lutas por uma vida mais digna, tais como as oriundas dos embates cotidianos e específicos?

Seguindo, em especial, o conceito de "quilombo" da intelectual negra Beatriz Nascimento, procuraremos refletir sobre as questões acima e ampliar a ideia de ação política a partir da análise de práticas sociais e de resistência no contexto brasileiro. Através de elementos particulares, tentaremos universalizar, dentro do território das lutas emergentes, 
específicas e locais, formas de ação e, principalmente, de subjetivação que favoreçam a compreensão das lutas que são desqualificadas se observadas por uma teoria política e pensamento tradicionais. Cotejaremos, também, as subjetividades "quilombolas" com a filosofia contemporânea de Michel Foucault, Gilles Deleuze e Félix Guattari, ao abordar os regimes capitalistas de produção de subjetividades.

\section{AS REVOLTAS POR UMA VIDA DIGNA}

Cena 1: 'interdição da via'

Um exemplo de luta por uma vida digna, e que se repete cotidianamente nas principais cidades do país, ocorreu no dia 15 de julho de 2016. O Jornal G1 da Rede Globo noticiou assim o fato: "Protesto pela morte de garoto terminou em violência na Av. Santa Inês. Os moradores atearam fogo a pneus e outros objetos e interditaram a via”. A descrição desta cena ocorrida no Jardim Peri, Zona Norte de São Paulo, assemelha-se a de uma guerrilha urbana: "Os manifestantes escreveram no chão o nome do adolescente e fizeram uma oração. Depois, ocuparam a via gritando o nome do outro adolescente que está em estado grave no hospital. No começo da noite, um carro trouxe uma carga de pneus e atearam fogo nos objetos. Um ônibus foi incendiado às $19 \mathrm{~h} 30$. Os policiais usaram bombas de gás e balas de borracha. Alguns manifestantes encapuzados atiravam pedras e fogos de artifício em direção aos agentes”. A manifestação iniciada após o atropelamento de dois jovens, em um local que por anos a população previa a possibilidade de uma tragédia, estourou em revolta logo após o enterro da vítima fatal. Era uma tarde em dia de semana corrido na cidade, como normalmente o é. Noite adentro ainda havia escaramuças da polícia e resistência de pequenos grupos, os quais utilizavam as vielas e a geografia conhecida como trunfo para se esquivarem da repressão policial ${ }^{4}$.

\footnotetext{
4 Disponível em http://g1.globo.com/sao-paulo/noticia/2016/07/pm-entra-em-confronto-commanifestantes-na-zona-norte-de-sp.html. Acessado em outubro de 2017.
} 
O acontecimento político certamente tem uma pretensão ou uma reivindicação e o direito tem a função de julgar a legitimidade desta demanda. Quando um coletivo ocupa uma avenida, toca fogo em pneus ou ônibus após a morte de um jovem negro e pobre morador do bairro de vielas apertadas e com esgoto sem tratamento, o que se pretende? Com que direito realizam o ato? Qual a consciência política dos indivíduos deste coletivo? Haveria um outro direito, uma outra ação política, para estas minorias paralelas?

A revolta, em especial na tradição do pensamento político brasileiro, é desqualificada como sendo um profundo sentimento subjetivo de injustiça, embebido no ressentimento do indivíduo paralisado pelo evento passado, e incapaz de encontrar expressão coletiva por carecer de organização e propósito político. A condição do revoltado seria a caracterização marcante e recorrente do negro, como nos aponta Abdias Nascimento:

Os quilombos são os precursores de nossa luta de hoje, quando, arriscando a vida, recusaram a imposição do trabalho forçado, dos novos valores culturais, novos deuses, nova língua, novo estilo de vida. São eles - os quilombolas - os primeiros elos dessa corrente de revolta que atravessa quatro séculos de história brasileira (1982, p. 102).

Observamos que em situações de extrema desigualdade social as instituições democráticas, por percurso histórico ou opção do presente, se mantêm pouco eficazes para lidar com o problema. Ou, o que é pior e mais comum, fazem

\footnotetext{
${ }^{5}$ Por "minorias paralelas" ou "coletivos paralelos" queremos significar os movimentos e eventos que fazem uso de certo vocabulário de direitos humanos e de suas estratégias mantendo, contudo, percursos autônomos. E, com isto, produzem novos arranjos para o vocabulário clássico, bem como outras estratégias e táticas de luta. O paralelismo os aproxima e distancia da tradição.
} 
destas condições as características próprias do processo de produção de riquezas.

Acessar as críticas dos coletivos paralelos seria uma tentativa de compreender e colaborar com processos de dessubjetivação de sujeitos históricos e das estratégias de dominação dos indivíduos aí enredados. Objetiva-se identificar formas de ação, as mais autônomas, e abrir possibilidades de lutas, enfrentamentos e oposições criativas. A análise destas críticas configura-se como parte das estratégias de insurgência de práticas locais e de resistência. É uma tentativa de deslocamento entre a pesquisa científica, a militância política e as lutas experimentadas no âmbito de direitos humanos em movimentos.

Acreditamos ser possível refletir sobre a ação por meio da análise sobre o discurso dos direitos humanos e, principalmente, dos efeitos de poder de seus mecanismos e estratégias. Compreendendo, por um lado, os direitos como a inscrição que delimita as formalidades do uso das forças de dominação e, por outro, o que mais nos interessa neste artigo, as estratégias e mecanismos como instrumentos de produção de efeitos de poder, disparadores de atos em defesa da vida e em prol de outras práticas sociais.

\section{OS LIMITES DA AÇÃO INSTITUCIONAL}

Nossa preocupação com a desqualificação de determinadas lutas começou, enquanto problema filosófico e de pesquisa, a partir das experimentações em torno da militância na Comissão de Familiares de Mortos e Desaparecidos Políti- 
cos da Ditadura ${ }^{6}$. Sendo este um movimento de direitos humanos, de denúncia dos crimes do regime civil-militar (1964-1985) e por atos de justiça, reparação e memória, sua dinâmica esteve sempre entre as aproximações e distanciamentos em relação às políticas públicas do Estado brasileiro (TELES, QUINALHA 2015).

Enquanto elemento de militância e de pesquisa trabalhamos a ideia de uma ação política na qual a produção de memórias sobre o passado de violência do Estado passaria, tanto em sua invisibilização, quanto em sua publicização, por uma estrutura de exceção, sempre em choque com o inscrito nas leis ${ }^{7}$. Outra questão que fundamentalmente acompanhou o percurso de minhas indagações foi a da desqualificação dos saberes produzidos pelas lutas de movimentos em torno do discurso dos direitos humanos. Para as políticas públicas estas são lutas consideradas como legítimas e justas, com certo conhecimento das contradições e conflitos, porém incapazes, segundo as vozes institucionais, de serem efetivas por não observarem as regras da governabilidade ou os limites dos pactos institucionais.

A democracia brasileira se constituiu durante a transição fundamentada em consensos obtidos via acordos das velhas oligarquias políticas e econômicas com os novos ato-

\footnotetext{
${ }^{6}$ Esta militância se deve ao fato de ter um tio na condição de desaparecido político. Trata-se de André Grabois, cuja eliminação e desaparecimento ocorreu durante ações do Exército na região do Araguaia (1973), onde iniciava-se a organização de um movimento de resistência à Ditadura. Além disso, minha família foi presa no ano de 1972, tendo eu, 4 anos, minha irmã, 5 anos, e meu primo, no sétimo de mês de gestação, nasceu no hospital militar de Brasília.

${ }^{7}$ Desenvolvi o argumento de que a exceção tem sido a marca da democracia, seja em seus aspectos autoritários ou os de mudança em alguns de meus principais trabalhos: "O que resta da ditadura: a exceção brasileira" (2010), organizado junto com Vladimir Safatle; "Democracia e Estado de Exceção" (2015); e, "O abismo na história" (2017).
} 
res surgidos durante o processo (SKIDMORE 1988). Iniciado ainda em 1974, com a chamada "abertura lenta, gradual e segura”, seguiu até a promulgação da Constituição de 1988, perfazendo o longo período de 14 anos. O prolongamento da transição indicou o controle para garantir que o novo regime não surgisse por meio de ruptura contundente com a Ditadura. A lógica do processo foi a de produção da governabilidade estável, mantendo os conflitos sob o manto discursivo da pacificação e da reconciliação. Este novo modo de governo, de coalizão, teria como estrutura central o paradigma do estado de exceção ${ }^{8}$.

Um exemplo da exceção nas políticas de memória é a montagem de uma comissão da verdade, instituto inexistente na Lei, para lidar com a questão da impunidade em relação às graves violações de direitos e da ausência dos corpos de desaparecidos políticos. O Estado brasileiro é signatário de vários tratados internacionais que condenam estes crimes e exigiriam a aplicação de ação penal e outras medidas sem a necessidade de uma instituição voltada à "reconciliação nacional" (como diz o artigo primeiro da lei que criou a Comissão Nacional da Verdade, em 2012). Outra grave exceção, originária e contínua, foi a interpretação de que a Lei de Anistia, de 1979, seria válida para promover

\footnotetext{
${ }^{8}$ A prática de um estado de exceção ou de emergência constante tornou-se paradigma para a governança e para a ação política. A medida de exceção não é apenas um direito especial do estado, mas um poder do soberano de suspender o próprio ordenamento. Os estados de exceção não estão fora da jurisdição da estrutura legal, pois, em princípio, são medidas soberanas de governos forçados a atitudes extremas diante de situações emergenciais. A medida de emergência se assemelha ao direito à legítima defesa, que deveria ser considerado dentro de situação de legalidade e, em favor desta, ser acionado. É uma medida pertencente aos estados de direito. De fato, mais importante do que a "verdadeira" necessidade é quem a diz. Não há necessidade em si, objetiva; há um dizer sobre ela, subjetivo, que foi do rei, no Estado absoluto, dos militares nas ditaduras e, no estado de direito, do legislativo, do poder executivo e do poder judiciário (AGAMBEN 2004).
} 
a impunidade dos agentes de Estado responsáveis por violações. Esta exceção foi confirmada, em maio de 2010, pelo Supremo Tribunal Federal (STF).

Desta forma, inaugurou-se uma democracia cuja herança das injustiças e carências do passado justificou a adoção de medidas consideradas necessárias e terapêuticas. Sob a promessa de desfazer os erros cometidos (sempre em outro governo, outro Estado, outra história) e diminuir o sofrimento social autoriza-se o acionamento de medidas emergenciais que dispensam os procedimentos democráticos. Constata-se, por outro lado, uma dinâmica dissonante e que nos permite compreender os movimentos sociais, cujas mobilizações apresentam pautas substancialmente diferentes. Os restos ausentes do cálculo de governo são as demandas destes movimentos, especialmente os de familiares e de vítimas diretas do período ditatorial. Para as instituições de Estado o que sobra participa da ambiguidade e dos conflitos internos ao governo, ora sendo valorizado e legitimando políticas públicas, ora sendo anulado, redundando em seu bloqueio.

No Brasil, sob o manto de fundamentação, legitimação e produção de sujeitos estáveis e prontos a se inserirem nas normas do direito, se produziu políticas de reparação, de mudança e inscrição de nomes de vítimas da ditadura em logradouros, de institucionalização da Comissão Nacional da Verdade, entre outras. Entretanto, isto não gerou processos de transformação, tais como a mudança do sistema de segurança pública, militarizado e sob a ideologia do "inimigo interno", ou os julgamentos penais dos torturadores e assassinos publicamente identificados e impunes. Mais grave, a permanência de mecanismos autoritários ocorreu 
sob a justificativa de se aplicar uma política de reconciliação e consolidação da democracia. Na administração da justiça de transição ${ }^{9}$ se reconhece discursivamente os limites das políticas públicas indicando que, em casos de saída de regimes autoritários se deve fazer aquilo que é possível, contudo, sem provocar instabilidades aos governos de consenso da democracia.

\section{CARTOGRAFIAS DOS DIREITOS HUMANOS EM LUTAS}

Cena 2: 'artilharia de frutas'

O dia 04 de abril de 1983 foi o momento da erupção, na Zona Sul de São Paulo, de uma revolta com protestos contra o desemprego. Conhecida à época como "Quebra-Quebra", sua narrativa foi apagada da história. Seja a nacional, ou a de esquerda, até mesmo da história das lutas sociais. Apesar disto, este movimento, por condições básicas de vida, como o emprego e contra o "alto custo de vida", mobilizou vocabulário de direitos humanos. A revista Veja, uma das maiores mídias semanais impressas e de linha editorial conservadora, assim descreveu o evento ${ }^{10}$ :

"Um braço ergueu-se no meio da multidão que começava a avançar e, rápido, alcançou a carroçaria de um caminhão Mercedes-Benz estacionado no Largo 13 de Maio, centro nervoso do bairro de Santo Amaro, em São Paulo. Ao exibir o troféu que conquistara - uma das

\footnotetext{
${ }^{9}$ A justiça de transição é uma política global, obtendo a recomendação da Organização das Nações Unidas (ONU) para sua aplicação. É indicada para novas democracias surgidas após conflitos violentos ou ditaduras. Tem quatro eixos principais: (1) direito à reparação, pecuniária e simbólica; (2) direito à memória para o esclarecimento dos fatos e homenagem às vítimas; (3) direito à verdade, com acesso às informações de arquivos e comissões de apuração das violações; e, (4) direito à justiça para a investigação e responsabilização jurídica. A principal estratégia de efetivação consiste em considerar os quatro eixos de ação como recomendações, negociando-os de acordo com as situações locais e recompondo as diretrizes a partir da correlação de forças em disputa. A maior qualidade da estratégia de justiça de transição é a maleabilidade de sua aplicação, o que se caracteriza, paradoxalmente, como um mecanismo de bloqueio das possibilidades de acesso a processos de ruptura e de transformações profundas. O direito se submete às condições políticas, as quais em geral se encontram dominadas por forças e pactos de controle e de produção do consenso sob o silêncio e a invisibilidade das lutas pelos direitos à vida.

${ }^{10}$ Revista Veja, n. 762, de 13 de abril de 1983, p. 26.
} 
40.000 laranjas amontoadas na carroceria -, um grupo desvinculou-se do bloco de 2000 participantes de uma passeata de protesto contra o desemprego, que minutos antes iniciara seu deslocamento rumo à Assembleia Legislativa, atacou o caminhão - e logo dezenas, centenas de laranjas passaram a devastar as vitrinas das lojas nas cercanias. Essa artilharia de frutas, desencadeada às 10 horas do dia 4 de abril de 1983, foi o primeiro e violento aviso de que um imenso barril de pólvora estava prestes a explodir na maior cidade brasileira. Nas 48 horas seguintes, São Paulo viveu sob a sensação de que a paz estava assassinada nas ruas".

A revolta duraria o restante da semana e ainda se espalharia para outras grandes cidades do país. As principais forças políticas dos pactos de transição rapidamente se prontificaram a desqualificar o caráter político do evento. "Provocação de infiltrados da direita", disseram as "forças progressistas e democráticas", movimento de desordem promovido por "forças radicais", disseram as instituições do quase se pôr da ditadura. $O$ presidente general Figueiredo classificou o evento como "atos de vandalismo que alarmaram a Nação" ${ }^{11}$. Nas palavras de ordem gritadas pelos manifestantes, contudo, o tom político e de protesto era claro: "Violência não, emprego sim", "Temos fome, temos fome", "Abaixo Figueiredo, queremos emprego" ${ }^{12}$.

Estes protestos acontecem como se fossem manifestações que excedessem o direito e a Lei, ameaçando o Estado, a paz, o mercado, a norma. "Por modesta que seja uma reivindicação, ela apresenta sempre um ponto que a axiomática não pode suportar, quando as pessoas protestam para elas mesmas levantarem seus próprios problemas a determinar, ao menos, as condições particulares sob as quais aqueles podem receber uma solução mais geral" (DELEUZE, GUATTARI 2012, p. 187). Neste tipo de acontecimento o direito tende a silenciar e invisibilizar as

\footnotetext{
${ }^{11}$ Cf. "Vandalismo atenta contra a democracia". In: O Estado de S. Paulo. São Paulo: 10 de abril de 1983 , p. 1.

${ }^{12}$ Cf. "Polícia ocupa Sé e impede aglomeração". In: Folha de S. Paulo: São Paulo, 7 de abril de 1983, p. 13.
} 
lutas, fazendo-as aparecerem como sem linguagem, ou sem a forma apropriada para um protesto. Não há uma representação, nenhuma ordem, falas desconexas e inaudiveis para os instrumentos de medição das instituições e do direito. "Talvez por isto que toda pretensão se transforma em grito, mesmo quando o grito permanece mudo ou inaudito" (LAPOUJADE 2015, p. 28).

As políticas positivas de diminuição do sofrimento social buscando curar, proteger, aliviar, incluir as vidas e corpos vulneráveis produzem uma série de efeitos, úteis às formas políticas, econômicas e sociais de dominação, as quais tal efetividade tem por função garantir e incrementar. Parece-nos que os direitos humanos estão inseridos em certa "economia política do corpo" cuja produtividade somente é possível mediante um regime de sujeição no qual o desamparado "é um instrumento político cuidadosamente organizado, calculado e utilizado" (FOUCAULT 2009, p. 28-29). Os coletivos atípicos ${ }^{13}$ também usam das tecnologias dos direitos humanos, nas funções que têm acesso, para resistirem contra seus efeitos de dominação. $O$ fato de serem

\footnotetext{
${ }^{13}$ Os coletivos atípicos seriam aqueles cujas subjetividades são consideradas vulneráveis e em estado de sofrimento social, segundo a gestão por meio de uma lógica de governo. Esta condição precária demandaria os cuidados via recursos utilizados para combater uma moléstia. Para os dispositivos das políticas públicas o remédio seria a institucionalização dos direitos humanos. São atípicos porque há algo de anormal em suas práticas e isto que supostamente possuem os submetem aos diagnósticos identificadores de patologias sociais alvos das políticas projetadas pelos especialistas. A atipicidade, ao se condensar em coletivos, potencializa a ação tendo como energia dinamizadora justamente a condição de vida, a qual, como veremos mais à frente, porta a experimentação de processos de resistência e de relações de poder (FOUCAULT 2005). A definição da atipicidade destes coletivos surge a partir, e em oposição, do caráter normatizador de certo sujeito típico da política pós-ditadura no país. Falamos da produção discursiva totalizante do sujeito "brasileiro", cujas subjetivações circulariam em torno da cordialidade, do orgulho, da felicidade, do nacionalismo moderado e do liberalismo político, características que levemente se modificam a depender da região ou do momento político.
} 
técnicas e estratégias, funções e efeitos, faz com este regime de produção de subjetivações políticas ganhe profundidade nas práticas e nas relações sociais sem se localizarem necessariamente nos aparelhos do Estado, nas leis e nas instituições de governo. As efetividades destes mecanismos se espraiam "ao nível dos indivíduos, dos corpos, dos gestos e dos comportamentos” (FOUCAULT 2009, p. 30).

Referimo-nos às lutas cujo valor da vida, em suas múltiplas existências, se encontra à frente das demandas. Por ser o corpo, a vida e suas relações o mobilizador, suas subjetividades, em medidas diferentes e com os acessos os mais variados, fazem uso de vocabulário similar ou emprestado ao discurso dos direitos humanos. É o caso, por exemplo, do Movimento Mães de Maio, reunião de familiares de vítimas da chacina de maio de 2006 promovida pelas instituições de segurança pública do Estado de São Paulo, quando mais de 500 pessoas foram assassinadas em apenas oito dias (MÃES DE MAIO 2012). O Movimento, em uma de suas publicações, apresenta com extrema clareza o alvo das revoltas e lutas:

Ainda no final de 2011, às voltas das festividades de natal, ocorreu um primeiro incêndio da favela do Moinho (comunidade a qual dedicamos este trabalho, na pessoas do guerreiro Milton Sales), que foi seguido pela operação "Dor e Sofrimento" na região da Luz / Santa Efigênia (mal-chamada de "Cracolândia"), seguido pelo inominável Massacre do Pinheirinho (que também homenageamos), uma série de outros despejos absurdos de ocupações na região central e nas periferias de São Paulo, uma sequência sem fim de favelas incendiadas criminosamente nos quatro cantos da cidade, a intensificação do encarceramento em massa no estado e, sobretudo, uma série ininterrupta de "ondas" de massacres periféricos, chacinas e execuções, decretando como banal a morte sumária de centenas de pessoas, a grande maioria jovens, civis, pobres, negros e periféricos [...] (MÃES 
DE MAIO 2012, p. 17).

Lista sem fim de um Estado desde sempre extremamente violento. Neste contexto, há que se ressignificar a noção de direitos humanos, ampliando sua concepção para além de uma ação de governo e de medidas de diminuição do sofrimento dos atingidos. Parece ser o caso de retomar o sentido de resistência e de estratégias de lutas para além da esfera dos direitos e do Estado. Para tanto, seria interessante alargar o conceito do que seja a ação política.

\section{Pensar uma AC̣ÃO POLÍtica AlARgAda}

Buscamos compreender o agir enquanto estratégias gerais de poder, portanto, procurarmos saber "por onde isso passa, como se passa, entre quem e quem, entre que ponto e que ponto, segundo quais procedimentos e com quais efeitos" (FOUCAULT 2008, p. 4). Por isto não buscaremos entender o que isto é, mas entender as relações entre as forças em disputa sem que se faça distinção destas relações com os seus mecanismos. Os próprios procedimentos são as relações, os mecanismos encadeiam os fenômenos da política. Desta forma, apreender as estratégias é encontrar e analisar como estes mecanismos atuam em situações específicas e em dados momentos, em determinado território. Não existiriam os mecanismos e procedimentos da ação política e, em outra dimensão, os acontecimentos e as relações efetivadas por eles. Trata-se de buscar os efeitos de saberes em constante produção nas lutas e desenvolvidos nas táticas e técnicas de poder.

A partir da emergência destas lutas, como o caso do 
"Movimento Mães de Maio", entre outros, buscamos as formas de resistência de corpos, saberes, técnicas, forças, desejos constituídos pelos efeitos de poder. Pensamos o poder como algo que se movimenta, em constante deslocamento e incidência, funcionando em rede, com seus elementos podendo serem submetidos e, também, exercerem estes poderes. $\mathrm{O}$ emergente seria a propriedade do movimento que faz aparecer, a partir de elementos simples e de um determinado ambiente, agenciamentos coletivos complexos. A emergência dos saberes normalmente não é previsível e indica uma qualificação nas práticas políticas locais. "[...] Um saber particular, um saber local, regional, um saber diferencial, incapaz de unanimidade e que deve sua força apenas à contundência que opõe a todos aqueles que o rodeiam" (FOUCAULT 2005, p. 12). Tais saberes não pertencem a nenhum dos elementos em particular, emergindo das relações aleatórias ou não dos singulares e, por isto, não podem ser preditos. Quanto mais elementos e mais abertura para as potências criativas, rupturas e novidades, maior o surgimento de saberes e deslocamentos.

Ao se instituir a Comissão Nacional da Verdade, em 2012, para tratar dos crimes da ditadura, as Mães de Maio passam a reivindicar a criação de uma comissão da verdade dos crimes da democracia. A conexão entre as lutas se estabeleceu por meio de redes e cartografias de afetos e subjetividades de grupos atingidos, os atípicos. Falarmos de cartografias e redes é pensar em diagramas ${ }^{14}$ das ideias e

\footnotetext{
${ }^{14}$ Gilles Deleuze assim define o diagrama em Foucault: "O diagrama não é mais o arquivo, auditivo ou visual, é o mapa, a cartografia, co-extensiva a todo o campo social. É uma máquina abstrata (...). É uma máquina quase muda e cega, embora seja ela que faça ver e falar" (DELEUZE 2006, p. 44).
} 
ações políticas cujas localizações proveem de relações múltiplas, passam por vários pontos e indicam uma visão espacializante e referenciada do social. Os diagramas desta geopolítica nos leva às reflexões sobre o que é periférico, marginalizado, invisibilizado e, por isto mesmo, desqualificado e desautorizado enquanto conhecimento. Trata-se de deslocar o olhar para o que é específico, menor, o que se encontra nas bordas da política. Aquilo que as sociabilidades dominantes buscam historicamente excluir e marginalizar, ou incluir através da exceção ${ }^{15}$, e que habitam os limites, as fronteiras.

Interessa-nos o olhar deslocado para as extremidades, em direção a uma cartografia de ação mais local, detalhada, onde as regras escritas e sua forma de organização se estendem para fora das instituições, técnicas e mecanismos na maior parte das vezes controlados. Servimo-nos do campo experimental de lutas que nos permitem acessar aspectos discursivos e estratégicos de investimento no valor da vida enquanto objeto do regime de produção dos corpos dóceis, sofridos e atendidos pelos remédios dos direitos. Nas cartografias das fronteiras, nos territórios descontínuos - por estarem em constante deslocamento - é possível localizar novas configurações do contemporâneo. Permite o acesso a outras visibilidades que o velho poder soberano, marcado pelo território-nação e pelo nascimento, limitava em termos

\footnotetext{
${ }^{15} \mathrm{~A}$ indistinção entre dentro e fora, incluir e excluir, será interpretada pela ideia de suspensões do direito, criando "zonas cinzentas", como escreveu Agamben nos seus trabalhos sobre o "estado de exceção" (2002). Temporárias e localizadas, perigosas para o poder único, mas também necessárias, normalmente lançam os debates sobre as lutas sociais para o campo binário do legítimo ou ilegítimo, legal ou ilegal, julgamento técnico ou político, pacífico ou violento, limitando o olhar escavador, capaz de ver mais abaixo da superfície discursiva dos conflitos e entendê-los também em suas características táticas, estratégicas e de esquiva dos poderes centrais ou dominantes.
} 
de análise. É o que podemos observar nos territórios palestinos, nas quais suas subjetividades sofrem a constante modificação de suas bordas, como nos apresenta Edward Said:

E logo adiante da fronteira entre "nós" e os "outros" está o perigoso território do não-pertencer, para o qual, em tempos primitivos, as pessoas eram banidas e onde, na era moderna, imensos agregados de humanidade permanecem como refugiados e pessoas deslocadas (SAID 2003, p. 50)

A condição palestina não é somente uma experiência particular. Diz sobre uma condição política contemporânea, do "mundo sem intervalos" (FANON 1979, p. 29), das subjetividades vividas como interrupções no "território do nãopertencer”.

O indivíduo, os sujeitos, participam enquanto intermediários, engrenagens das máquinas políticas e podem também serem considerados resultantes destes processos. Tal como em experimentos físico químicos, seriam efeitos de fenômenos reproduzidos sob o controle e condução das técnicas e tecnologias de dispositivos, no caso, do dispositivo de direitos. Pois, "o que faz que um corpo, gestos, discursos, desejos sejam identificados e constituídos como indivíduos, é precisamente isso um dos efeitos primeiros do poder". Assim, o indivíduo é o território da ação, bem como seu efeito, "o poder transita pelo indivíduo que ele constituiu” (FOUCAULT 2005, p. 35).

\section{REGIMES NÔMADES DE SUBJETIVAÇÕES}

A questão dos territórios nas novas configurações da ação política indica algo que se encontra além da divisão geográfica, se apresentando mais como "uma identificação pro- 
funda da pessoa com a terra", diz Beatriz Nascimento (In: GERBER $\left.1989^{16}\right)$. E complementa indicando o quanto a disputa em torno dos territórios imprime regimes de subjetivação: "a terra é o meu quilombo. Meu espaço é meu quilombo. Onde eu estou, eu estou. Quando eu estou, eu sou" (GERBER 1989).

Há, para Beatriz Nascimento, uma memória corporal que compõe as subjetivações dos coletivos em situação de violação da vida. Esta lembrança-corpo não é resultado de um encadeamento causal, mas se inscreve no sujeito através destes territórios que possuem as "características de fronteira, não só geográfica, como também demográfica, econômica e cultural" (NASCIMENTO 2006a, p. 115). A autora aponta a "relação entre intelecto e memória, entre cabeça e corpo, entre pessoa e terra" (RATZ 2006, p. 63) como a subjetivação constituinte das formas de lutas e resistências. A “palavra yorubá, língua utilizada na religião dos orixás”, para significar o que chamamos de regime de produção de certas subjetividades políticas é "Ôrí":

Ori significa uma inserção a um novo estágio da vida, a uma nova vida, um novo encontro. Ele se estabelece enquanto rito e só por aqueles que sabem fazer com que uma cabeça se articule consigo mesma e se complete com o seu passado, com o seu presente, com o seu futuro, com a sua origem e com o seu momento (In: GERBER 1989).

\footnotetext{
${ }^{16}$ Boa parte das reflexões de Beatriz Nascimento nos foi legada por meio de material audiovisual. O principal deles é o documentário "Ôrí", dirigido por Raquel Gerber, com textos e narração da própria Beatriz Nascimento. Note-se a importância da oralidade na produção e transmissão de conhecimento nas culturas africanas, valorizando a trama de teias temporais e de múltiplas singularidades em vivências comuns. Tal forma de comunicação e transmissão de saberes garante a polifonia das narrativas, as várias versões do acontecimento. Carrega também a performatividade de ocorrer de modos próprios a depender do espaço, do tempo, do silêncio, da cadência, da palavra, da voz, enfim, da complexidade de fatores e elementos políticos constituintes da experimentação.
} 
A "identificação profunda do corpo com a terra" (In: GERBER 1989) contribui para a elaboração da memória coletiva fundamentada em uma territorialidade que promove o desequilíbrio das fronteiras. A subjetividade se configura por meio de territórios que a delimita e correlaciona e que "se projeta a partir das diferenças, do rompimento numa outra unidade" (In: GERBER 1989), em outros fluxos e agenciamentos. "O território pode ser relativo tanto a um espaço vivido, quanto a um sistema percebido no seio do qual um sujeito se sente "em casa" (GUATTARI, ROLNIK 1999, p. 323).

Um território fechado, apropriado para a posse de um poder qualquer, gera toda uma série de comportamentos e normatizações, bem como consolida técnicas de disciplinarização e discursos de conteúdos de dominação para produzir o corpo dócil. Contudo, no território "desterritorializado" do corpo-quilombo, com suas fronteiras em deslocamento, se abrem "linhas de fuga". "[...] A fuga implica numa reação ao colonialismo" (NASCIMENTO 2006a, p. 122) e seria "o primeiro ato de alguém que não se reconhece como propriedade de outro” (GERBER 1989), de onde deriva sua importância para desestabilizar o disciplinar e o normal.

Ampliam-se as potências do ser, mergulham-se os sujeitos "num imenso movimento [...] no sentido de que seus territórios 'originais' se desfazem ininterruptamente" (GUATTARI, ROLNIK 1999, p. 323). Desarticulação de fronteiras observadas por Beatriz Nascimento nos quilombos brasileiros, cuja experimentação ocorria através de "diversos deslocamentos" com "características nômades" (NASCIMENTO 2006b, p. 118), adaptando o quilombo ao 
espaço geopolítico em que as relações sociais e comerciais ocorressem de modo mais dinâmico e eficiente.

"O espaço nômade é marcado apenas por traços que se apagam e se deslocam com o trajeto" (DELEUZE, GUATTARI 1999, p. 43). Os traços, ao se deslocarem e se transformarem neste processo, demonstram a potência de adaptação das lutas em torno dos valores dos direitos humanos. Suas próprias características remetem a questões cotidianas, do vivido no chão das relações de poder, nas extremidades onde se efetivam os poderes soberanos e disciplinares. Deslocado, nômade, em mutação, os sujeitos ganham a dimensão ampla que, de modo especial, as ações políticas podem conceder a uma subjetividade. Beatriz Nascimento, crítica ao olhar eurocêntrico, do "homem branco" e da "terra azul", descreve a potência da subjetivação quilombola, uma espécie de cartografia dos afetos "oceânicos" e de luta:

Quilombo é aquele espaço geográfico onde o homem tem a sensação de oceano. Raquel, você precisa se sentir na serra da Barriga. Toda a energia cósmica entra no seu corpo. Eu fico grande numa serra. Eu fico assim, Raquel, alta, parecendo os Imbangala. Sabe como é? Essa coisa de negro mesmo. Mas é de negro porque é o homem ligado à terra. É o homem que mais conhece a terra que nem aqueles horizontes Dogon. É o homem preto, cor da lama, cor da terra. Porque Gagarin viu a terra azul, mas existe a terra preta. Existe essa terra que é terra, que é a coisa que a gente mais tem medo de perder. É o pó. É o pó da terra, que é uma coisa que se equilibra com outros gases, que dá fundamento (GERBER 1989).

"Eu sou atlântica”, dito por Beatriz Nascimento, se refere a todo este território-água de conexão do passado com o presente, esta potência oceânica de se transformar e se desterritorializar quando em ação coletiva de resistência. 


\section{CONTINUIDADE HISTÓRICA E CONECTIVIDADE}

Beatriz Nascimento, ao refletir acerca do racismo institucional dentro da universidade brasileira, apresentou seu ponto de partida para a crítica de certo vitimismo que ligaria o negro a um evento passado, bloqueando suas subjetividades autônomas e libertadoras:

Quando cheguei na universidade a coisa que mais me chocava era o eterno estudo sobre o escravo. Como se nós só tivéssemos existido dentro da nação como mão de obra escrava, como mão de obra para fazendas e para mineração (GERBER 1989).

Manter uma subjetividade presa a um evento passado, no caso a escravidão, produz sua coisificação. Enquanto ação política, reserva a estes sujeitos um devir objeto, a passividade da espera de algum remédio de diminuição de seus sofrimentos. Certo olhar sobre os direitos humanos os lança no lugar do especialista pronto a produzir e efetivar a medicação da anomalia que atinge a subjetividade das vítimas. Beatriz Nascimento encara o negro a partir de outro olhar, a partir da experiência histórica que ele viveu, mas sem o sentido de resgate de algo que ficou no passado. Para as lutas específicas, "a identificação total com o fraco, o vencido, o inumano, é insuficiente, ao nível da luta do diaa-dia [...]. Enquanto necessitarmos criar e recriar heróis, codificar e recodificar símbolos, somos, ainda, muito infelizes" (NASCIMENTO 2006c, p. 126). A história, o já experimentado, funciona mais como conexão aos saberes e afetos que ainda habitam os corpos no tempo presente, justamente por eles se encontrarem sob o impacto de uma sociedade racista.

Uma das mais fortes características das lutas específicas 
e dos coletivos paralelos é a conectividade de seus saberes e estratégias, sua potência em assumir memórias de conflitos passados, mesmo que sem uma relação orgânica entre movimentos. É a forma de ação que permite ao Movimento Mães de Maio mobilizar dizeres semelhantes a outras movimentações de direitos humanos. Apesar de formado por pessoas não oriundas de militância política, reunidas em torno da catástrofe em suas vidas por consequência da violência de Estado, um de seus primeiros símbolos foi o da bandeira do Brasil em preto e branco, com cerca de metade de seu desenho original e com a inscrição ao centro: "contra o terrorismo de Estado”. A conexão com uma história política se verifica tanto no nome, referência direta às Madres da Plaza de Mayo, da Argentina, quanto no lema, com os dizeres engajados em discurso que se encontraria entre as denúncias de direitos humanos e as lutas anticapitalistas.

"[...] Não é difícil estabelecer conexão" entre a história dos quilombos e as formas de resistência nos territórios negros no país (NASCIMENTO 2006b, p. 119). O quilombo, enquanto continuidade de uma experimentação política específica, permanece na memória-corpo através de "estratégias, táticas de tomada de regiões, de ocupações” (GERBER 1989). Nossas questões se referem aos mecanismos, estratégias, associações, conexões, rupturas e transformações que lutas pela vida digna ensejam. As estratégias possuem maleabilidade e plasticidade maior do que as estruturas. Estas habitam os espaços, as instituições, as leis. Aquelas, enquanto modos de se fazer e de se conduzir as ações, habitam, ou melhor, são as próprias subjetivações dos indivíduos. Estes, por sua vez, são os que habitam e, ao mesmo tempo, constituem as estratégias. Experimentação 


\section{destas subjetividades oceânicas e suas conectividades pude- ram ser vistas nas ocupações de escolas secundaristas, em 2015:}

Cena 3: 'as meninas lideraram as ocupações'

Uma delas é Lilith Cristina Passos Moreira, 15 anos. Ela teve contato com o feminismo em redes sociais. Passou a prestar atenção aos papéis feminino e masculino e apresentou um trabalho escolar que inicialmente nem entraria na questão. 'Comecei a ouvir opiniões e fiquei inconformada com o pensamento de um entrevistado que iria compor a minha apresentação. E me dei conta do machismo', conta. Participar da ocupação da escola Maria José, na Bela Vista (bairro da região central de São Paulo), durante um mês, foi importante para aprimorar sua percepção. 'Durante o movimento escancarou-se o processo de opressão existente sobre os estudantes de escolas públicas, mais ainda quando se trata de mulheres negras', diz Lilith. 'Por isso, foi muito natural que as meninas tenham liderado as ocupações. Formou-se uma unidade entre as mulheres, que logo montaram um coletivo para continuar discutindo e atuando'.

$\mathrm{Na}$ ocupação, ela lembra, a primeira polêmica surgiu na divisão do trabalho. Em uma assembleia, um dos participantes sugeriu que as meninas ficassem na cozinha. 'Pra quê...'. Após conversarem, criaram cotas para as comissões de alimentação e segurança, o que garantiu participação equilibrada nas atividades. 'Foi um processo como eu acredito que deva acontecer para construir uma nova sociedade, mais livre', afirma. Para ela, o mais difícil tem sido lidar com a conduta de alguns educadores que não levam o assunto a sério. Lilith cita o exemplo de um professor de História que em sala de aula considerou 'vitimizador' o tema da violência contra as mulheres na redação do Exame Nacional do Ensino Médio (Enem)”"17.

Oue se mantém, ainda que com modificações e adaptações, e exercem a conectividade, são as estratégias, tanto

\footnotetext{
${ }^{17}$ Cf. "Lute como uma menina. Ameaças de retrocesso dão gás ao feminismo". In: Revista do Brasil, 13 de julho de 2016, número 119. Disponível em http://www.redebrasilatual.com.br/revistas/119/lute-como-uma-menina-ameacas-de-retrocessos-dao-gasao-feminismo-6595.html, acessado em outubro de 2017.
} 
as de dominação, quanto as de resistência. É assim que surge a subjetivação oceânica das meninas nas ocupações: elas são afetadas pelo machismo. E as lutas cotidianas, como deparar-se e resistir à proposição de que deveriam ir para a cozinha, acionam a percepção da experiência comum e liberam as potências do agir em conjunto.

As fronteiras em deslocamento, como vimos, permitem à memória quilombo ativar a potência de interseccionalidades ${ }^{18}$ conectadas pelo modo de vida e pelo passado em comum. Assim, no terreiro, no baile funk ou no rap, na geração tombamento ou em um duelo de slam, teríamos a conexão de corpos negros com a experimentação de uma mesma cartografia de afetos e de estratégias de vivências. Contudo, "não se tratava, no meu entender, exatamente de sobrevivência ou resistência cultural, embora venhamos a utilizar estes termos algumas vezes, como referência científica. $\mathrm{O}$ que procuramos neste estudo é a continuidade histórica" (NASCIMENTO 2006a, p. 109) ou, como acrescentamos, a conectividade paralela entre lutas por uma vida digna.

O corpo-mapa traria no gingado da capoeira a potência da esquiva, tal como nas práticas de resistência em favelas, nas periferias ou nos quilombos contemporâneos se mantém as estratégias de desvio dos golpes sofridos para poder se reorganizar em um movimento de contra-ataque mais

\footnotetext{
${ }^{18}$ Kimberlé Crenshaw, intelectual estadunidense, ao analisar as relações entre gênero, classe e raça definiu a interseccionalidade como uma "conceituação do problema que busca capturar as consequências estruturais e dinâmicas da interação entre dois ou mais eixos da subordinação. Ela trata especificamente da forma pela qual o racismo, o patriarcalismo, a opressão de classe e outros sistemas discriminatórios criam desigualdades básicas que estruturam as posições relativas de mulheres, raças, etnias, classes e outras" (2002, p. 177).
} 
eficaz. Desta forma, o quilombismo "passou a ser sinônimo de povo negro, sinônimo de comportamento do negro e esperança para uma melhor sociedade" (NASCIMENTO 2006b, p. 124). Trata-se do "acoplamento dos conhecimentos eruditos e das memórias locais, acoplamento que permite a constituição de um saber histórico das lutas e a utilização desse saber nas táticas atuais" (FOUCAULT 2005, p. 13). A continuidade histórica, segundo Beatriz Nascimento, ou a conectividade, como nomeamos, seria algo como um "mundo sem intervalos", "a vida dos homens continuando aparentemente sem clivagens, embora achatada pelos vários processos e formas de dominação" (NASCIMENTO 2006a, p. 110).

\section{CONCLUSÕES}

São as lutas por creches, contra os preços elevados dos alimentos, por mais empregos, por um outro transporte público, pela vida. Em um primeiro olhar, sob um viés da política representativa e institucionalizada, pode-se ver nestes acontecimentos reivindicações ingênuas, de segunda categoria, até mesmo impróprias se tomarem para si o espaço público, sem vínculos com um programa político e, por isto, desqualificadas. Pode-se suspeitar que se trate de estratégias obscuras e marionetadas por forças ocultas. As revoltas de junho de 2013, iniciadas sob a chave de uma resistência à materialidade de alguns centavos a mais na passagem do transporte público, parece ter sido o vetor de todo um conflito em torno de estratégias de dominação e resistência, de controle das vidas e de sua circulação. São momentos nos quais os direitos humanos podem ser lidos como técnicas 
políticas de resistência dos corpos e de seus coletivos.

Não pretendemos, com os argumentos apresentados, definir um conceito de ação política ou, ao alargar os eventos concebidos como políticos, redefini-lo sob novos parâmetros. Estamos em uma experimentação filosófica de compreender uma versão possível do caráter das lutas e dos acontecimentos políticos. Abordamos o conceito como uma formulação que diz sobre o acontecimento. Pensar o conceito como versão implica compreender o mundo por meio de uma diversidade de representações filosóficas, tanto quantas são as inteligibilidades em circulação. Cada uma delas e suas representações veem a si e às outras perspectivas filosóficas como um modo singular de abordar determinado acontecimento. Pretendemos com este artigo tomar as análises das experiências políticas como "dotadas de uma significação filosófica, ou como potencialmente capazes de um uso filosófico" (CASTRO 2015, p. 219).

$\mathrm{O}$ instituído e formalizado entra em disputas territoriais com a ocorrência de lutas e saberes menores. Nestes casos, a condição de menoridade representa as práticas de resistência de coletivos e subjetividades que se encontram às bordas do que é tradicionalmente o político. Por isto, pela própria estrutura do estar dentro e fora ao mesmo tempo, a experimentação do menor é política. E as expressões dos coletivos memorizados tornam-se necessariamente ações de resistência ou de revolta, "seu espaço exíguo faz que cada caso individual seja imediatamente ligado à política" (DELEUZE, GUATTARI 2014, p. 36).

Este indivíduo, por sua condição da experimentação comum da atipicidade, porta as configurações da subjetivação oceânica. Regime de produção de subjetividades políti- 
cas mais autônomas, o "oceânico" se apresenta nos atos de coletivos ou movimentos paralelos. Uma de suas principais características seria a habilidade de estabelecer conectividades entre as lutas a partir de estratégias semelhantes que dialogam nas cartografias de desejos e afetos das práticas de resistência. Elemento fundamental destes acontecimentos parece ser a disputa política por territórios em que as fronteiras não se encontram claramente delimitadas, o que pode favorecer a criação de outros repertórios e tecnologias políticas, dinamizando e ampliando o alcance das lutas. Ao ocupar as vias ou as escolas, ao burlar os bloqueios e se dirigirem aos territórios interditados, ao estabelecer outras formas de relacionamento que não os das normatizações sociais, os coletivos se abrem para potências de transformação da experiência comum dos territórios que habitam.

Abstract: The purpose of this article is to reflect on how local struggles and their movements around the discourse of human rights can be elevated to the condition of political action. It is the attempt to broaden the concept of politics in view of the power of transformation contained in the collectives of subjectivities bearing common experiences of violence and suffering. Using the concept of quilombo in Beatriz Nascimento, we will seek to justify the extension of the idea of politics from two configurations: the territorial dispute and the connectivity between specific knowledges from the struggles. To do so, we will compare the thinking of Nascimento with the contemporary philosophy of Michel Foucault, Gilles Deleuze and Félix Guattari. The hypothesis is that the concept of political action would require a widening in its formulation to encompass the multiple forms of daily resistance.

Keywords: connectivity; territory; quilombo; body; political action; struggle for rights.

\section{REFERÊNCIAS}

AGAMBEN, Giorgio. Homo Sacer: o poder soberano e a vida nua. Trad. Henrique Burigo. Belo Horizonte: UFMG, 
2002.

. Estado de exceção. Trad. Iraci D. Poleti. São Paulo: Boitempo, 2004.

ARENDT, Hannah. A condição humana. Trad. Roberto Raposo. Revisão técnica e Apresentação Adriano Correia. Rio de Janeiro: Forense Universitária, 2010.

CASTRO, Eduardo Viveiros de. Metafísicas canibais: elementos para uma antropologia pós-estrutural. São Paulo: Cosac Naify, 2015.

CRENSHAW, Kimberlé. Documento para o encontro de especialistas em aspectos da discriminação racial relativos ao gênero. In: Revista Estudos Feministas. Vol. 10, número 1. Florianópolis: 2002, pp. 171-188.

DELEUZE, Gilles. Foucault. Trad. Claudia Sant'Anna Martins. São Paulo: Brasiliense, 2006.

DELEUZE, Gilles e GUATTARI, Félix. Kafka: por uma literatura menor. Trad. Cintia Vieira da Silva. Belo Horizonte: Autêntica, 2014.

. Mil platôs. Capitalismo e esquizofrenia 2. Vol. 4. Trad. Suely Rolnik. São Paulo: Editora 34, 2012.

FANON, Frantz. Os condenados da terra. Trad. J. L. de Melo. Rio de Janeiro: Civilização Brasileira, 1979.

FOUCAULT, Michel. Em defesa da sociedade. Curso no Collège de France (1975-1976). Trad. Maria Ermantina Galvão. São Paulo: Martins Fontes, 2005. . Vigiar e Punir: nascimento da prisão. Trad. Raquel 
Ramalhete. Petrópolis/RJ: Vozes, 2009.

GUATTARI, Félix e ROLNIK, Sueli. Micropolítica. Cartografias do desejo. Petrópolis/RJ: Vozes, 1999.

GERBER, Raquel (Direção). Ôrí. Fotografia de Hermano Penna, Pedro Farkas, Jorge Bodanzky, entre outros, música de Naná Vasconcelos e arranjos de Teese Gohl. 1989. Disponível

em:

https://www.youtube.com/watch?v=DBxLx8D99b4 e acessado em" novembro de 2017.

LAPOUJADE, David. Deleuze, os movimentos aberrantes. Trad. Laymert Garcia dos Santos. São Paulo: n-1, 2015.

MÃES DE MAIO, Movimento. Periferia grita. São Paulo: Fundo Brasil de Direitos Humanos e Fundação Rosa Luxemburg, 2012.

NASCIMENTO, Maria Beatriz. Kilombo e memória comunitária: um estudo de caso. In: RATZ, Alex. Eu sou atlântica. Sobre a trajetória de vida de Beatriz Nascimento. São Paulo: Instituto Kuanza e Imprensa Oficial: 2006a, pp. 109-116 (artigo publicado pela primeira vez em 1982).

- O conceito de quilombo e a resistência negra. In: RATZ, Alex. Eu sou atlântica. Sobre a trajetória de vida de Beatriz Nascimento. São Paulo: Instituto Kuanza e Imprensa Oficial: 2006b, pp. 117-125 (artigo publicado pela primeira vez em 1985).

. Daquilo que se chama cultura. In: RATZ, Alex. Eu sou atlântica. Sobre a trajetória de vida de Beatriz Nascimento. São Paulo: Instituto Kuanza e Imprensa Oficial: 
2006c, pp. 125-126 (artigo publicado pela primeira vez em 1986).

NASCIMENTO, Abdias. O Negro Revoltado. Rio de Janeiro: Nova Fronteira, 1982.

NEGRI, Antonio e GUATTARI, Félix. As verdades nômades. Por novos espaços de liberdade. Trad. Mario A. Marino e Jefferson Viel. São Paulo: Autonomia Literária e Politeia, 2017.

RATZ, Alex. Eu sou atlântica. Sobre a trajetória de vida de Beatriz Nascimento. São Paulo: Instituto Kuanza e Imprensa Oficial: 2006.

SAID, Edward W. Reflexões sobre o exílio e outros ensaios. Trad. Pedro Maia Soares. São Paulo: Companhia das Letras, 2003.

SKIDMORE, Thomas. Brasil: de Castelo a Tancredo (1964-1985). Rio de Janeiro: Paz e Terra, 1988.

TELES, Edson \& SAFATLE, Vladimir (Orgs.). O que resta da ditadura: a exceção brasileira. São Paulo: Boitempo, 2010.

TELES, Edson \& QUINALHA, Renan. Achievements and Limits of Transitional Justice in Brazil. In: SCHNEIDER, Nina e ESPARZA, Marcia (orgs.). "Transitional Justice" and the Legacies of State Violence in Latin America. Lexington/Rowman and Littlefield: 2015, pp. 19-36.

TELES, Edson. Democracia e estado de exceção. Transição e memória política no Brasil e na África do Sul. São Paulo: Unifesp, 2015. 
. O abismo na história: ensaios sobre o Brasil em tempos de Comissão da Verdade (2009-2015). São Paulo: Alameda, 2017 (no prelo). 